Gut, 1987, 28, S1, 193-195

\title{
Effect of pancreatic atrophy and hypertrophy on the small intestine
}

\author{
G ADLER, W HAUSMANN, K ELSEBACH, B GÖKE, H LORENZ-MEYER, \\ L HERBERG, AND R ARNOLD
}

From the Division of Gastroenterology, Department of Internal Medicine, Philipps University of Marburg, and the Diabetes Research Center, University of Düsseldorf, FRG

SUMMARY Intestinal enzyme activities were investigated in mice with spontaneously occurring exocrine pancreatic insufficiency (EPI), in rats after induction of pancreatic insufficiency by intraductal injection of oleic acid, and in rats after feeding a proteinase inhibitor (Camostate) which induced a marked pancreatic hypertrophy. An increase in saccharase activity and in vitro uptake of L-phenylalanine was found in EPI mice, while activities of alkaline phosphatase and lactase were not altered. In oleic acid induced pancreatic insufficiency and in pancreatic hypertrophy no alterations in enzyme activities were observed. Morphometric analysis revealed no alterations in mucosal surface of EPI mice. It was suggested that the small intestine adapts functionally to severe and long lasting pancreatic insufficiency, but not to pancreatic hypertrophy.

In exocrine pancreatic insufficiency an increase in intestinal enzyme activities of disaccharidases have been described in man and in animals. ${ }^{1-4}$ It was suggested that the loss of pancreatic enzymes decreased the turnover of brush border enzymes. ${ }^{5}$ On the other side, after ligation of the pancreatic duct, exocrine insufficiency was paralleled by a decrease of the absorbing area of the intestine. ${ }^{6}$ The aim of the present study was to analyse whether changes in intestinal enzyme activities were correlated with alterations in intestinal cell mass and transport function. Additionally we investigated whether intestinal adaptive changes depend on the severity of pancreatic insufficiency, and occur in pancreatic hypertrophy.

\section{Methods}

\section{ANIMALS}

In $12 \mathrm{CBA} / \mathrm{J}$ mice the spontaneously occurring exocrine pancreatic insufficiency syndrome (EPI) was diagnosed on the basis of rapid weight loss and fatty yellow stools four weeks before the intestinal studies. ${ }^{7}$ Twelve healthy adult $\mathrm{CBA} / \mathrm{J}$ mice served as controls.

In 18 rats pancreatic insufficiency was induced by a single injection of $50 \mu \mathrm{l}$ oleic acid into the pancreatic duct. ${ }^{8}$ Intestinal studies were done after six weeks.

Address for correspondence: Prof Dr G Adler, Zentrum für Innere Medizin, Baldingerstrasse, D-3550 Marburg, FRG.
Saline injected animals and untreated rats served as controls. Hypertrophy of rat pancreas was induced by daily feeding the proteinase inhibitor Camostate $(400 \mathrm{mg} / \mathrm{kg}){ }^{9}$ After five, 10 , and 15 days of feeding intestinal studies were undertaken. Animals were killed under ether anaesthesia. Small intestines were removed, rinsed in cold, $0.9 \%$ saline, measured, and weighed. From a $10 \mathrm{~cm}$ segment which started $20 \mathrm{~cm}$ distal the pylorus, the mucosa was scraped off and homogenised. DNA, protein, saccharase, lactase, and alkaline phosphatase were measured according to standard procedures. ${ }^{10-13}$ In EPI mice a jejunal segment $(100 \mathrm{mg})$ was removed to investigate the in vitro uptake of ${ }^{14} \mathrm{C}$-L-phenylalanine according to Robinson et al. ${ }^{14}$ Morphometric analysis of villus height and width, and crypt length of the jejunum was carried out on HE-stained sections.

\section{RESULTS}

In mice with severe exocrine pancreatic insufficiency (EPI) a marked increase in jejunal activity of saccharase was found, while the activities of alkaline phosphatase and lactase were not different from healthy CBA/J mice (Fig. 1). In oleic acid induced pancreatic insufficiency in rats the jejunal enzyme activities of lactase, saccharase, and alkaline phosphatase were the same as from saline treated and untreated rats (Table 1). Morphometric analysis of the jejunum in EPI mice revealed a significant decrease in villus height, and an increase in villus width, while 


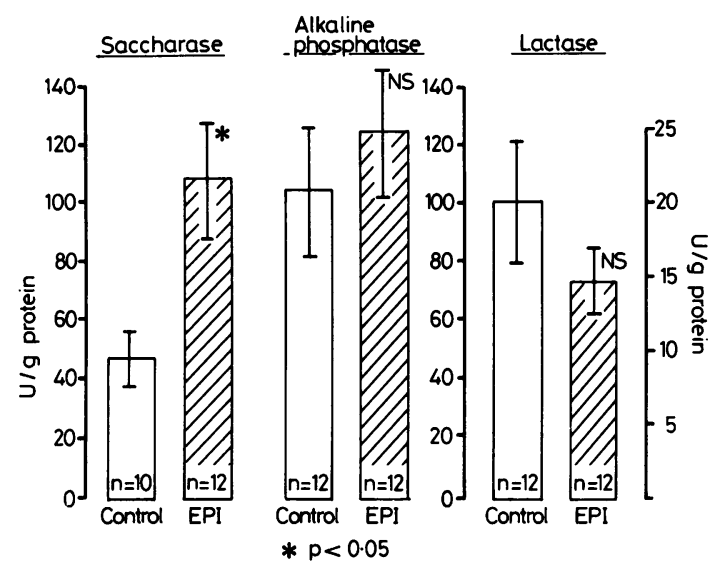

Fig. 1 Intestinal enzyme activities in mice with exocrine pancreatic insufficiency (EPI) compared with healthy $C B A / J$ mice. Values are means $\pm S E M$.

Table 1 Intestinal enzyme activities after oleic acidinduced pancreatic insufficiency in rats.

\begin{tabular}{lccc}
\hline Enzyme $(U / g$ protein $)$ & Oleic acid & Saline & $\begin{array}{l}\text { Untreated } \\
\text { controls }\end{array}$ \\
\hline Saccharase & $141 \pm 66$ & $145 \pm 38$ & $172 \pm 43$ \\
Lactase & $17 \pm 7$ & $13 \pm 6$ & $17 \pm 4$ \\
Alkaline phosphatase & $256 \pm 172$ & $262 \pm 157$ & $398 \pm 161$ \\
\hline
\end{tabular}

Values are means \pm SD
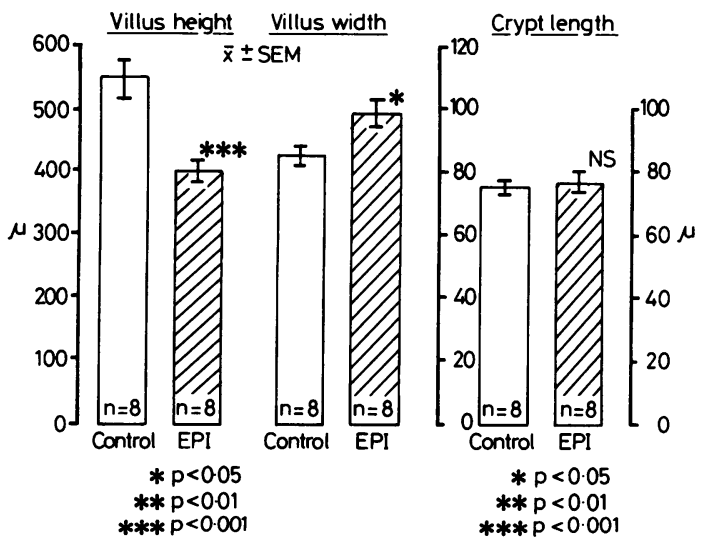

Fig. 2 Morphometric analysis of jejunal mucosa in mice with exocrine pancreatic insufficiency (EPI) compared with healthy $C B A / J$ mice. Values are means $+S E M$.

crypt length was not altered (Fig. 2). In rats with oleic acid induced pancreatic insufficiency no differences in jejunal morphology were found when compared with controls (data not shown). In vitro uptake of ${ }^{14} \mathrm{C}-\mathrm{L}$ phenylalanine was increased in EPI mice compared

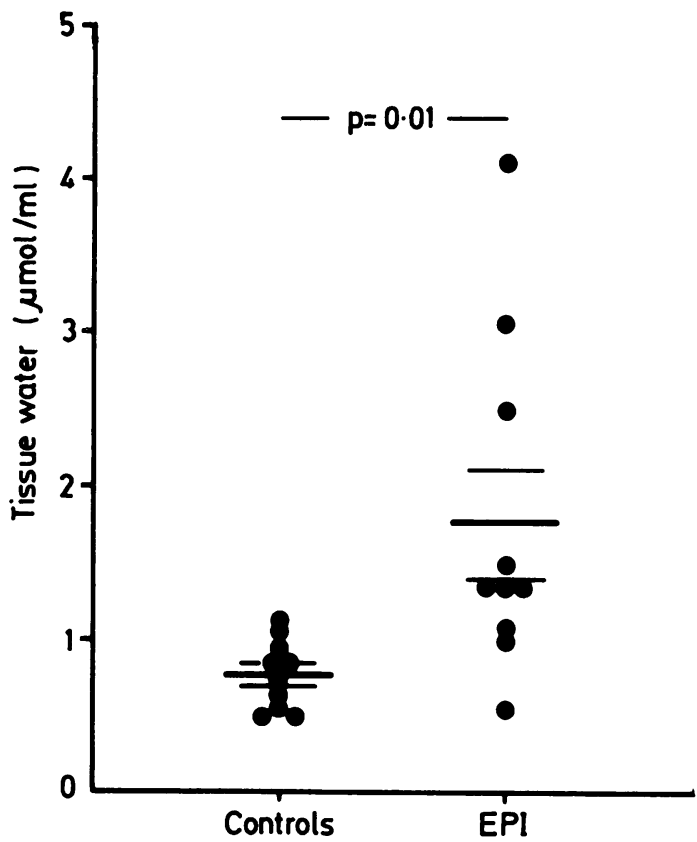

Fig. 3 In vitro uptake of ${ }^{14} \mathrm{C}$-L-phenylalanine in EPI mice compared with healthy $C B A / J$ mice.

Table 2 Intestinal enzyme activities in rats after feeding the proteinase inhibitor Camostate.

\begin{tabular}{lccc}
\hline Enzyme $(U / g$ protein $)$ & $\begin{array}{c}\text { Days of } \\
\text { feeding }\end{array}$ & Camostate & Controls \\
\hline Saccharase & 5 & $172 \pm 32$ & $96 \pm 28$ \\
& 10 & $103 \pm 30$ & $134 \pm 34$ \\
Lactase & 15 & $125 \pm 27$ & $189 \pm 23$ \\
& 5 & $15 \pm 3$ & $16 \pm 5$ \\
Alkaline phosphatase & 10 & $13 \pm 4$ & $20 \pm 6$ \\
& 15 & $14 \pm 3$ & $17 \pm 4$ \\
& 5 & $268 \pm 55$ & $179 \pm 53$ \\
& 10 & $170 \pm 46$ & $251 \pm 66$ \\
& 15 & $280 \pm 61$ & $183 \pm 38$ \\
\hline
\end{tabular}

Values are means $\pm S D$

with healthy CBA/J mice (Fig. 3). Pancreatic hypertrophy by feeding a proteinase inhibitor had no effect on length, wet weight, DNA, and protein content of the small intestine (data not shown). No significant differences in enzymatic activity of saccharase, lactase, and alkaline phosphatase in jejunum were observed after feeding the inhibitor for five, 10, and 15 days (Table 2). Morphometric analysis of villi and crypts gave similar results when compared with controls.

\section{DISCUSSION}

In the present study intestinal adaptation to pancreatic insufficiency was seen in severely diseased EPI 
mice only. The EPI mice presented with weight loss, steatorrhea, and destroyed pancreas which was replaced by adipose tissue. They could only survive when they ingested the pancreatic enzyme containing faeces of healthy mice. ${ }^{7}$ In oleic acid induced pancreatic insufficiency the functional impairment was only moderate, as the rats still gained weight and did not show deficiency syndromes, although $97 \%$ of the exocrine pancreas was destructed. ${ }^{8}$ In this model of pancreatic insufficiency no changes in intestinal enzyme content and morphology were observed. We therefore concluded that severity and duration of pancreatic insufficiency are important factors in intestinal adaptation. A similar conclusion was drawn from studies in patients with pancreatic insufficiency. ${ }^{2}$ Patients with steatorrhea had higher maltase and sucrase activities than those without steatorrhea. At variance with these studies is the observation of Creutzfeldt $e t$ al that in rats with pancreatic atrophy induced by feeding a copper deficient diet and penicillamine, intestinal enzyme activities were increased only in the proximal part of the small intestine. ${ }^{4}$

An explanation for increased activity of some intestinal enzymes in pancreatic insufficiency was given by Alpers et al. ${ }^{3515}$ Because disaccharidases and transport proteins are associated with the brush border they could preferentially be degraded by pancreatic enzymes which stick to the membrane of intestinal mucosa. As was seen in the duct ligation model of pancreatic insufficiency by Balas and coworkers, we found a significant reduction in villus height in mice with severe pancreatic insufficiency. ${ }^{6}$ As the villi became smaller but broader, the total cell surface was not significantly altered.

A direct trophic effect of pancreatic secretions on intestinal mucosa was suggested from studies in which the duodenal papilla was transplanted to other regions of the intestine, ${ }^{16}$ but was doubted by Ecknauer and coworkers. ${ }^{17}$ In our study, daily feeding of a proteinase inhibitor for up to 15 days induced pancreatic hypersecretion and a strong increase in plasma CCK which had no trophic effect on the small bowel. ${ }^{9}$ Whether CCK alone has a trophic effect on intestinal mucosa was controversely discussed in different studies. ${ }^{41819}$

We conclude that the small intestine adapts functionally only to severe and long lasting pancreatic insufficiency, and not to pancreatic hypertrophy induced by endogenous CCK.

\section{References}

1 Arvanitakis C, Olsen WA. Intestinal mucosa disaccharidases in chronic pancreatitis. Am J Dig Dis 1974; 19: 417-21.
2 Caspary WF, Winckler K, Lankisch PG, Creutzfeldt W. Influence of exocrine and endocrine pancreatic function on intestinal brush border enzymatic activities. Gut 1975; 16: 89-92.

3 Kwong WKL, Seetharam B, Alpers DH. Effect of exocrine pancreatic insufficiency on small intestine in the mouse. Gastroenterology 1978; 74: 1277-82.

4 Creutzfeldt W, Fölsch UR, Elsenhans B, Ballmann M, Conlon JM. Adaptation of the small intestine to induced maldigestion in rats. Scand $J$ Gastroenterol 1985; 20: suppl 112: 45-53.

5 Alpers DH, Tedesco FJ. The possible role of pancreatic proteases in the turnover of intestinal brush border proteins. Biochim Biophys Acta 1975; 401 : 28-40.

6 Balas D, Senegas-Balas F, Bertrand C, Frexinos J, Ribet A. Effects of pancreatic duct ligation on the hamster intestinal mucosa. Digestion 1980; 20: 157-67.

7 Eppig JJ, Leiter EH. Exocrine pancreatic insufficiency (EPI) syndrome in CBA/J mice. I. Ultrastructural study. Am J Pathol 1977; 86: 17-30.

8 Mundlos S, Adler G, Schaar M, Koop I, Arnold R. Exocrine pancreatic function in oleic acid-induced pancreatic insufficiency in rats. Pancreas 1986; 1: 2936.

9 Göke B, Printz H, Koop I, Rausch U, Richter G, Arnold R, Adler G. Endogenous CCK-release and pancreatic growth in rats after feeding a proteinase inhibitor (Camostate). Pancreas 1986; 1: 509-15.

10 Burton KA. Study of the conditions and mechanism of the diphenylamine reaction for the calorimetric estimation of desoxyribonucleic acid. Biochem $J$ 1956; 62: 315-23.

11 Lowry OH, Rosenbrough NJ, Farr AL, Randall RJ. Protein measurement with Folin phenol reagent. $J$ Biol Chem 1951; 193: 265-75.

12 Dahlquist PA. Method for assay of intestinal dissacharidases. Anal Biochem 1964; 7: 18-25.

13 Bessey OA, Lowry OH, Brock MJ. Methods for rapid determination of alkaline phosphatase with 5 cubic millimeter serum. J Biol Chem 1946; 164: 321-9.

14 Robinson JWL, Antonioli IA, Mirkowitch V. The intestinal response to ischemia. Arch Pharmacol Exp Pathol 1966; 225: 178-91.

15 Alpers DH, Kinzie JL. Regulation of small intestinal protein metabolism. Gastroenterology 1973; 64: 47196.

16 Altmann GG. Influence of bile and pancreatic secretions on the size of the intestinal villi in the rat. Am J Anat 1971; 132: 167-78.

17 Ecknauer R, Clarke RM, Feyerabend G. An experimental model for studies on the effects of food and digestive secretions on the digestive-absorptive capacity of rat small intestine. J Clin Chem Clin Biochem 1977; 15: $361-6$.

18 Hughes CA, Bates T, Dowling RH. Cholecystokinin and secretin prevent the intestinal mucosal hypoplasia of total parenteral nutrition in the dog. Gastroenterology 1978; 75 : 34-41.

19 Weser E, Bell D, Tawil T. Effects of octapeptidecholecystokinin, secretin, and glucagon on intestinal mucosal growth in parenterally nourished rats. Dig Dis Sci 1981 ; 26: 409-16. 